\title{
Effect of SiC on Microstructure, Phase Evolution, and Mechanical Properties of Spark-Plasma-Sintered High-Entropy Ceramic Composite
}

\author{
Hanzhu Zhang (1) and Farid Akhtar* \\ Division of Materials Science, Luleå University of Technology, 97187 Luleå, Sweden; hanzhu.zhang@ltu.se \\ * Correspondence: farid.akhtar@ltu.se
}

Received: 10 August 2020; Accepted: 16 September 2020; Published: 18 September 2020

\begin{abstract}
Ultra-high temperature ceramic composites have been widely investigated due to their improved sinterability and superior mechanical properties compared to monolithic ceramics. In this work, high-entropy boron-carbide ceramic/SiC composites with different $\mathrm{SiC}$ content were synthesized from multicomponent carbides $\mathrm{HfC}, \mathrm{Mo}_{2} \mathrm{C}, \mathrm{TaC}, \mathrm{TiC}, \mathrm{B}_{4} \mathrm{C}$, and $\mathrm{SiC}$ in spark plasma sintering (SPS) from $1600{ }^{\circ} \mathrm{C}$ to $2000{ }^{\circ} \mathrm{C}$. It was found that the $\mathrm{SiC}$ addition tailors the phase formation and mechanical properties of the high-entropy ceramic (HEC) composites. The microhardness and fracture toughness of the HEC composites sintered at $2000{ }^{\circ} \mathrm{C}$ were improved from $20.3 \mathrm{GPa}$ and 3.14 MPa.m ${ }^{1 / 2}$ to $26.9 \mathrm{GPa}$ and $5.95 \mathrm{MPa} \cdot \mathrm{m}^{1 / 2}$, with increasing SiC content from HEC-(SiC)0 $(0 \mathrm{vol} . \%)$ to HEC-(SiC)3.0 (37 vol. \%). The addition of SiC (37 vol. \%) to the carbide precursors resulted in the formation of two high-entropy ceramic phases with two different crystal structures, face-centered cubic (FCC) structure, and hexagonal structure. The volume fraction ratio between the hexagonal and FCC high-entropy phases increased from 0.36 to 0.76 when $\mathrm{SiC}$ volume fraction was increased in the composites from HEC-(SiC)0 to HEC-(SiC)3.0, suggesting the stabilization of the hexagonal high-entropy phase over the FCC phase with SiC addition.
\end{abstract}

Keywords: high-entropy ceramic; $\mathrm{SiC}$ composite; spark plasma sintering; phase transformation; mechanical properties

\section{Introduction}

High-entropy ceramics (HECs) that are manufactured from multiple ceramic precursors, such as transition metal carbides and borides, have shown great potential to replace conventional ceramic in certain application fields due to their superior properties including excellent mechanical performance, oxidation resistance, and thermal-electrical properties [1-3]. Inherited from the high-entropy alloys (HEAs) [4], HECs can reveal simple solid solution crystal structures attributed to the high-entropy structure stabilization [5]. In the field of refractory HECs, high-entropy carbides and high-entropy borides synthesized from group IV, V, and VI Metal-C and Metal-B ceramics are the most studied systems to date. Gild et al. [3] and Castle et al. [2] reported the first high-entropy diborides in 2016 and high-entropy carbide in 2018, respectively. The synthesized HECs showed simple solid solution structure with the same crystal structure as the constituent ceramic compounds, i.e., face-centered cubic (FCC) B1 structure for the HE-carbides and hexagonal $\mathrm{AlB}_{2}$ structure for the HE-diborides. In the stated crystal structures, the principal metal atoms occupy the cationic sites randomly while the non-metals occupy the anionic sites. Both of the HE-carbides and HE-borides showed enhancement of mechanical properties as compared to monolithic ceramic compounds [2,3]. Since then, the research on refractory HECs was intensively stimulated, and superior mechanical properties including enhanced fracture toughness [6,7] and elastic modulus [8,9] were discovered. Apart from the improvement of mechanical 
properties, HE-carbides $\left(\mathrm{Hf}_{0.2} \mathrm{Zr}_{0.2} \mathrm{Ta}_{0.2} \mathrm{Nb}_{0.2} \mathrm{Ti}_{0.2}\right) \mathrm{C}$ synthesized by Yan et al. [10] showed unexpected lower thermal diffusivity $\left(3.6 \mathrm{~mm}^{2} / \mathrm{s}\right)$ than the monocarbides, making them promising for insulating applications. Similar improvement of hardness and low thermal conductivity was discovered in HE-silicides $\left(\mathrm{Mo}_{0.2} \mathrm{Nb}_{0.2} \mathrm{Ta}_{0.2} \mathrm{Ti}_{0.2} \mathrm{~W}_{0.2}\right) \mathrm{Si}_{2}$ that are lately sintered by Gild et al. [11] and Qin et al. [12].

The general phase formation rule for high-entropy materials is established based on two main factors; (1) thermodynamic effect that is based on the Gibbs energy, (2) geometric effect which for HEAs commonly refers to the atomic size difference among the constituent components. To stabilize the high-entropy solid solution phase, minimization of the Gibbs energy is achieved by the characteristic compositional complexity-induced increase of the mixing entropy in both HEAs and HECs. In terms of the geometric factor, elements with small difference in atomic size and even elemental electronegativity are preferred for designing HEAs. For HECs, especially carbides and borides, where the components are commonly covalently bonded ceramic compounds, most of the so-far reported HECs (carbides and borides) were synthesized from components with the same crystal structure, as a faster inter-diffusion rate of the atoms within the same lattice structure promotes the formation of solid solutions $[10,13,14]$, even though Sarker et al. [8] have reported that a single-phase high-entropy carbide can be formed from precursors with different crystal structure. Based on this assumption, the combination of elements are significantly limited, for instance, in the refractory metal carbide system, six carbides from group IV and $\mathrm{V}$ (Ti-, Zr-, Hf-, $\mathrm{V}-, \mathrm{Nb}-$, and Ta-carbide) have cubic crystal structure while the whole group VI carbides (Cr-, Mo-, and W-carbide) are non-cubic structures, resulting in one third of the carbides which are not usually considered when designing HECs. In addition, the formation of high-entropy ceramic compounds with one certain anionic element, oxygen, carbon, or boron, limits the exploration of HECs only to the certain variation of cationic elements.

HECs usually consist of anion/cation sublattices. In case of most of the reported HECs with one non-metal element, the anionic sublattice is uniform, thereby the high configurational entropy in HECs is mainly contributed by the random configuration of the cationic sublattice [15]. Theoretically, the addition of more than one anion increases the total configurational entropy in HECs by introducing the configurational entropy in the anionic lattice, which could contribute to the stabilization of the high-entropy solid solution structure. Our previous study on high-entropy $\mathrm{B}_{4}\left(\mathrm{HfMo}_{2} \mathrm{TaTi}\right) \mathrm{C}$ ceramic shows that from $\mathrm{HfC}, \mathrm{Mo}_{2} \mathrm{C}, \mathrm{TaC}, \mathrm{TiC}$, and $\mathrm{B}_{4} \mathrm{C}$, a high-entropy boron-carbide solid solution with hexagonal crystal structure can be formed $[16,17]$. The metal atoms and carbon/boron atoms occupy lattice sites of (0001) and (0002) planes, respectively, in the hexagonal lattice. The result suggests the possibility of synthesizing HECs from a system with structure diversity $\left(\mathrm{Mo}_{2} \mathrm{C}\right.$ and $\mathrm{B}_{4} \mathrm{C}$ have hexagonal and rhombohedral crystal structure, respectively) as well as complex elemental diversity of metals and non-metals. The usage of precursor ceramics that have various different crystal structures and the incorporation of more than one anionic element can increase the elemental diversity and the potential of discovering designing new HECs.

Refractory ceramic carbides and diborides of transition metals like $\mathrm{ZrB}_{2}, \mathrm{HfB}_{2}, \mathrm{HfC}$, and $\mathrm{TaC}$ are known as ultra-high temperature ceramics (UHTCs) that show superior properties under elevated temperatures including high melting points $\left(>2000{ }^{\circ} \mathrm{C}\right)$, high hardness, excellent oxidation, and corrosion resistance [18-21]. The high-temperature capability makes them attractive candidates for high-temperature applications such as automotive, aerospace, and cutting tool industries. Due to high melting point and slow self-diffusion coefficients, the sintering of UHTCs generally requires high sintering temperature and pressure, which can induce coarsening of the microstructure of the UHTCs [22]. Ceramic additives like AlN [23], $\mathrm{MoSi}_{2}$ [20,21], and SiC [24,25] have been added to UHTC to improve sinterability and optimization of the microstructure [26,27]. Additionally, the inherent brittleness of the UHTCs leads to low fracture toughness and poor thermal shock resistance. Among the sintering additive candidates, $\mathrm{SiC}$ whiskers $\left(\mathrm{SiC}_{\mathrm{w}}\right)$ with high surface area to volume ratio can effectively contribute to the fracture toughness by crack bridging and deflecting mechanisms [28,29], and $\mathrm{SiC}_{\mathrm{W}}$-reinforced UHTCs have been widely studied and reported to have enhanced mechanical properties including the strength, impact resistance, and thermal shock resistance [30-34]. HECs 
containing both carbon and boron, as the new class of UHTCs have superior mechanical properties than conventional UHTCs. The incorporation of $\mathrm{SiC}$ with HECs is aiming at achieving further improvement of the mechanical performance of UHTCs composites. SiC-reinforced high-entropy carbides have been reported to show remarkable oxidation resistance by Wang et al. [35] and mechanical properties by $\mathrm{Lu}$ et al. [36]. Our previous studies on HECs-SiC composite showed that a SiC-reinforced high-entropy $\mathrm{B}_{4}\left(\mathrm{HfMo}_{2} \mathrm{TaTi}\right) \mathrm{C} / \mathrm{SiC}$ ceramic composite reveals superior mechanical properties and remarkable oxidation resistance under different temperature conditions. In addition, $\mathrm{SiC}$ was found to play an essential role in the phase formation during the sintering of high-entropy boron-carbide/SiC ceramic composite [17]. In this study, high-entropy boron-carbide ceramic composites with different SiC content (from 0 to 37 vol. \%) were synthesized via spark plasma sintering (SPS). The densification process was investigated by comparing the relative densities of the composites sintered at different temperatures. The sintered high-entropy boron-carbide/SiC composites, HEC-(SiC)x, exhibited improved densification and superior hardness and fracture toughness. The composition, microstructure, and phase evolution were investigated using electron microscopy, energy dispersive spectroscopy (EDS), and X-ray diffraction analysis.

\section{Materials and Methods}

\subsection{Processing}

HfC $\left(<1.25 \mu \mathrm{m}\right.$, Sigma Aldrich, St. Louis, MO, USA), $\mathrm{Mo}_{2} \mathrm{C}$ ( -325 mesh, Alfa Aesar, Haverhill, MA, USA), TaC ( $1 \mu \mathrm{m}$, US Research Nanomaterials, Houston, TX, USA), TiC ( $2 \mu \mathrm{m}$, Alfa Aesar), $\mathrm{B}_{4} \mathrm{C}$ (1-7 $\mu \mathrm{m}$, Alfa Aesar), and $\mathrm{SiC}$ whiskers (cubic $\beta-\mathrm{SiC}, 1.5 \mu \mathrm{m}$ diameter and approximately $18 \mu \mathrm{m}$ length, Alfa Aesar) were utilized as starting materials for sintering. The sintering precursors were prepared by measuring and mixing the carbide powders with a molar ratio of $\mathrm{HfC}: \mathrm{Mo}_{2} \mathrm{C}: \mathrm{TaC}: \mathrm{TiC}: \mathrm{B}_{4} \mathrm{C}: \mathrm{SiC}=$ 1:0.5:1:1:0.5: $\mathrm{x}(\mathrm{x}=0,0.5,1.0,2.0,3.0)$. The carbide powder mixtures were ball-milled for $3 \mathrm{~h}$ with $\mathrm{ZrO}_{2}$ balls of $1 \mathrm{~mm}$ diameter (ball to powder mass ratio $=5: 1$ ) using ethanol as milling media in order to prevent overheating and undesired wearing of the $\mathrm{ZrO}_{2}$ balls during the milling process. After ball milling, the suspensions of powder mixtures were sieved and dried in an oven at $60^{\circ} \mathrm{C}$.

The sintering of the powders was conducted in SPS-530ET (Dr. Sinter Spark Plasma Sintering System, Fuji electronic industrial Co., Ltd., Tsurugashima, Japan) installed in a glovebox. The powders were filled into a graphite die with a diameter of $8 \mathrm{~mm}$ and sintered at $1600{ }^{\circ} \mathrm{C}, 1800{ }^{\circ} \mathrm{C}$, and $2000{ }^{\circ} \mathrm{C}$ with a heating rate of $200{ }^{\circ} \mathrm{C} / \mathrm{min}$ and a holding time of $10 \mathrm{~min}$. The whole sintering process was conducted under vacuum with a constant uniaxial pressure of $60 \mathrm{MPa}$ being applied to the graphite die. All the specimens were free-cooled to room temperature in an ultra-high vacuum. The sintered HEC compositions are denoted as HEC-(SiC)0, HEC-(SiC)0.5, HEC-(SiC)1.0, HEC-(SiC)2.0, and HEC-(SiC)3.0 in the discussion section.

\subsection{Characterization}

The sintered composites were polished using SiC grinding papers up to 600 grit for the measurement of densities. The density of the sintered specimens was measured using the Archimedes water immersion method. The theoretical densities of the HEC composites was calculated using rule of mixtures. The sintered specimens were further polished following the standard metallurgical sample preparation procedure, using $\mathrm{SiC}$ grinding paper and a diamond polishing agent for a microstructural study. The microstructural investigation and elemental composition analysis were conducted on the Scanning Electron Microscope JSM-IT300 (JEOL, Tokyo, Japan) equipped with an energy dispersive spectrometer (EDS), calibrated with Cobalt. Based on the contrast of each phase in the micrographs recorded using the backscattered electrons, the volume fraction of each phase was evaluated by applying image thresholding in the image analysis software ImageJ. For each specimen, five images at the same magnification $(\times 250)$ were recorded from different locations for image analysis. $\mathrm{X}$-ray diffraction $(\mathrm{XRD})$ was conducted using an X-ray diffractometer (Empyrean, PANalytical, Malvern, 
UK) with $\mathrm{Cu}-\mathrm{K} \alpha$ radiation (wavelength $0.154 \mathrm{~nm}$ ). The $\mathrm{XRD}$ data was investigated using the software PANalytical X'Pert HighscorePlus with the PDF-4 + database.

The microhardness of the sintered composites was measured using the Matsuzawa MXT-CX microhardness tester (Matsuzawa Co., Japan) at different loading conditions, 200 g, 300 g, 500 g, and $1000 \mathrm{~g}$. For each indentation load, at least eleven indentations were performed to obtain the average Vickers hardness. The indentation fracture toughness of the composites was measured at the indentation load of $1000 \mathrm{~g}$. The indentation cracks on the sample surface were observed and measured in JSM-IT300 (JEOL, Tokyo, Japan). The fracture toughness $K_{I C}$ was calculated by using the formula proposed by Evans and Charles $[37,38]$ :

$$
K_{I C}=0.16(c / a)^{-1.5}(H \sqrt{a})
$$

where $c$ is the length of the cracks, $a$ is the half length of the diagonal of the Vickers indentation, and $H$ is the Vickers hardness.

All the characterizations were performed at room temperature.

\section{Results}

\subsection{SiC Effect on Densification and Mechanical Properties}

The relative densities as a function of the sintering temperature in Figure 1a show that the relative density of HEC-(SiC)x composites increases with the increase in the SPS sintering temperature. Moreover, the HEC-(SiC)x composite reveals higher densification with increasing $\mathrm{SiC}$ content at $1600{ }^{\circ} \mathrm{C}$, with a relative density increasing from $72.5 \%$ for HEC-(SiC)0 to $81 \%$ for the HEC-(SiC)3.0 composite. As the sintering temperature increases to $1800^{\circ} \mathrm{C}$, the composites containing $\mathrm{SiC}$ whiskers show a relative density above $97 \%$, while the HEC-(SiC)0 composite without $\mathrm{SiC}$ whiskers shows a comparatively lower relative density of $92 \%$. The composites sintered at $2000{ }^{\circ} \mathrm{C}$ are densified to near theoretical density. For each of the HEC-(SiC)x composites, the increase of sintering temperature resulted in higher relative density due to the promoted diffusive mass-transport at higher sintering temperature [39].

In general, the addition of a constituent in form of a whisker to a powder body can hinder the densification of a ceramic powder body during sintering [40]. Therefore, liquid phase sintering [41,42] or pressure-assisted sintering is required to achieve a dense whisker-reinforced ceramic composite [43]. In our case, the sintering at $1800{ }^{\circ} \mathrm{C}$ and $2000{ }^{\circ} \mathrm{C}$ at $60 \mathrm{MPa}$ resulted in relative densities above $99 \%$ of theoretical density, suggesting that the pressure assisted sintering resulted in enhanced densification of HEC-(SiC)x composites containing $\mathrm{SiC}$ in form of whiskers. Moreover, the experimentally observed higher densification of the HEC-(SiC)x composites with the increase in the volume fraction of $\mathrm{SiC}$ during pressure-assisted sintering, Figure 1a, is likely to be the result of the lower melting point of the $\mathrm{SiC}\left(2730^{\circ} \mathrm{C}\right)$ compared to other UHTC constituents such as $\mathrm{TaC}\left(3880^{\circ} \mathrm{C}\right)$, $\operatorname{HfC}\left(3900^{\circ} \mathrm{C}\right)$, and $\operatorname{TiC}\left(3160^{\circ} \mathrm{C}\right)$. The increase in the volume fraction of a low-melting-point component $\mathrm{SiC}$ in the HEC-(SiC)x composites, which has relatively higher plasticity and lower resistance to grain boundary sliding at high temperatures [44], can effectively enhance the densification. Lu et al. [36] has reported the promoted densification of high-entropy carbide $\left(\mathrm{Ti}_{0.2} \mathrm{Zr}_{0.2} \mathrm{Hf}_{0.2} \mathrm{Nb}_{0.2} \mathrm{Ta}_{0.2}\right) \mathrm{C}$ by adding 20 vol. \% SiC. A similar promotion of the densification of other UHTCs by adding $\mathrm{SiC}$ has also been reported, such as the relative density of hot pressed $\mathrm{TiB}_{2}-\mathrm{SiC}$ composites could increase from 4.33 to $4.39 \mathrm{~g} / \mathrm{cm}^{3}$ when the $\mathrm{SiC}_{\mathrm{w}}$ content was increased from 0 to 15 vol. \% [45]. Shahedi Asl et al. reported that the relative density of the TiC-SiC composite increased from $99.23 \%$ to $>100 \%$ when the $\mathrm{SiC}_{\mathrm{w}}$ content was increased from 0 to 30 vol. \%, sintered by SPS [46]. 
a
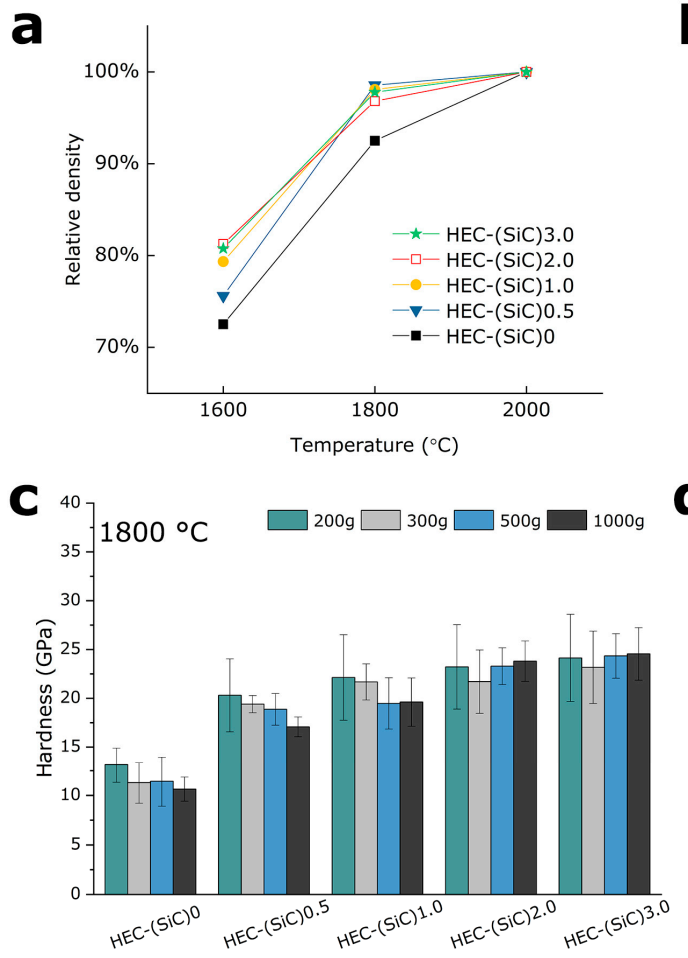

b
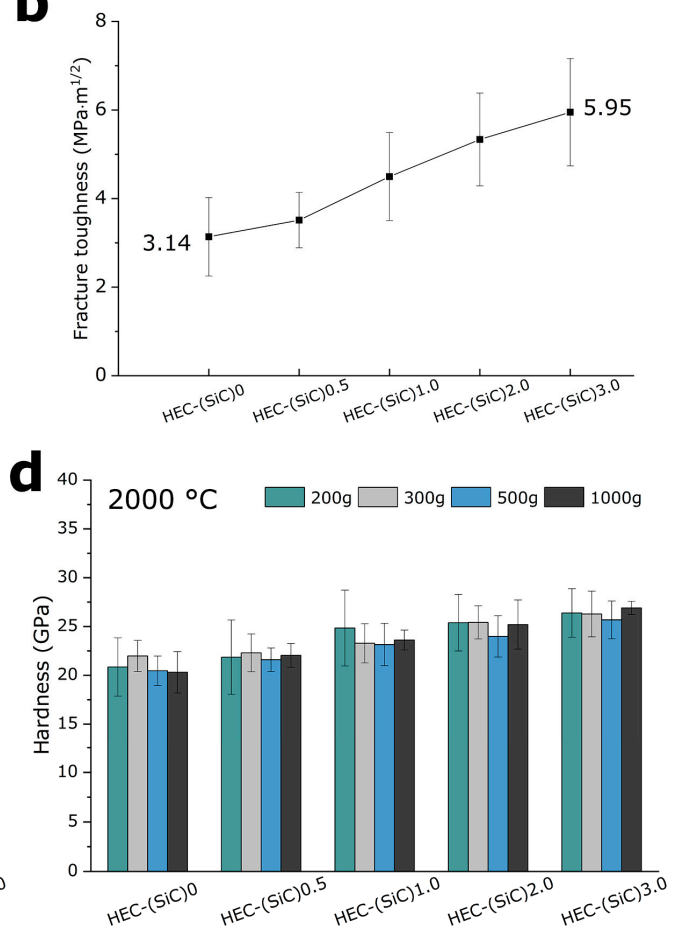

Figure 1. (a) The relative densities of high-entropy ceramic (HEC)-(SiC) $x(x=0,0.5,1.0,2.0,3.0)$ composites at different sintering temperatures, (b) fracture toughness of the composite from $2000{ }^{\circ} \mathrm{C}$, $(\mathbf{c}, \mathbf{d})$ are the Vickers hardness of HEC-(SiC)x composite at $1800^{\circ} \mathrm{C}$ and $2000^{\circ} \mathrm{C}$, respectively, as function of different indentation load.

Figure $1 \mathrm{~b}-\mathrm{d}$ summarizes the mechanical properties of the HEC-(SiC)x composites sintered at $1800{ }^{\circ} \mathrm{C}$ and $2000{ }^{\circ} \mathrm{C}$. It can be seen (Figure 1d) that the applied load does not significantly affect the hardness of HEC-(SiC)x composites sintered at $2000{ }^{\circ} \mathrm{C}$ during indentation due to nearly dense composites. On the other hand, the hardness of HEC-(SiC)x composites sintered at $1800^{\circ} \mathrm{C}$ (Figure 1c) varies with the applied load, especially for the composite with lower relative density (HEC-(SiC)0), because of the residual porosity. The enhancement of the hardness with increasing SiC content was observed in both 1800 and $2000{ }^{\circ} \mathrm{C}$ composites, possibly due to the hindered grain growth of HECs phases, which can consequently increase the composite hardness by a grain boundary strengthening effect [47]. By comparing Figure 1c,d, it is evident that the hardness of the HEC-(SiC)x composites increases with higher sintering temperature, which can be correlated to the higher densification, i.e., reduction of residual porosity in the composites sintered at $2000^{\circ} \mathrm{C}$ compared to $1800{ }^{\circ} \mathrm{C}$.

All the HEC-(SiC)x composites sintered at $2000^{\circ} \mathrm{C}$ show hardness values from 20.3 to $26.9 \mathrm{GPa}$ under the indentation load of $1000 \mathrm{~g}$ (Figure 1d). Meanwhile, $\mathrm{SiC}$ is known to have a hardness of 24.5-28.2 GPa [18]; therefore, it can be deduced that the hardness of the high-entropy ceramic phases lies within the range similar to $\mathrm{SiC}$. This explains why no visible influence on the hardness of the HEC-(SiC)x composites with increasing $\mathrm{SiC}$ content is observed. The hardness values of the sintered HEC-(SiC)x composites are comparable to the reported high-entropy carbides with similar compositions, such as $\left(\mathrm{Zr}_{0.25} \mathrm{Nb}_{0.25} \mathrm{Ti}_{0.25} \mathrm{~V}_{0.25}\right) \mathrm{C}$ [6], (MoNbTaVW)C [8], and (MoNbTaTiVW)C(N) [48], and with hardness values of $30.3 \mathrm{GPa}, 27 \mathrm{GPa}$, and $28 \mathrm{GPa}$, respectively, as well as SiC-reinforced UHTCs composites which are based on refractory metal carbides and borides. Shahedi Asl et al. reported $\mathrm{SiC}_{\mathrm{w}}$-reinforced $\mathrm{TiC}$ with a hardness of approximately $25 \mathrm{GPa}$ and with a SiC volume fraction of $20 \%$ [46], and Farhadi et al. synthesized a $\mathrm{TiB}_{2}-\mathrm{SiC}_{\mathrm{w}}(30 \mathrm{vol}$. \%) composite with a hardness of $30 \mathrm{GPa}$ [45].

The fracture toughness of HEC-(SiC)x composites sintered at $2000{ }^{\circ} \mathrm{C}$ were calculated by analyzing the indentation cracks on the sample surface. Shown in Figure 1b, the fracture toughness of the HECs composites increased $89 \%$, from $3.14 \mathrm{MPa} \cdot \mathrm{m}^{1 / 2}$ for HEC-(SiC)0 to $5.95 \mathrm{MPa} \cdot \mathrm{m}^{1 / 2}$ for HEC-(SiC)3.0, 
which is comparable to the $20 \mathrm{vol} . \% \mathrm{SiC}$-reinforced high-entropy carbide $\left(5.24 \mathrm{MPa} \cdot \mathrm{m}^{1 / 2}\right)$ as reported by Lu et al. [36]. The correlated crack morphologies of HEC-(SiC)0, 1.0, and 3.0 are shown in Figure 2. It can be seen that the indentation cracks in the HEC-(SiC)0 composite are propagating through the bright phase (transgranular) and along the boundary of the gray phase (intergranular), producing a continuing straight crack path on the sample surface. With the $\mathrm{SiC}$ addition to the composite, $\mathrm{SiC}$ grains interact with the crack propagation and enhance fracture toughness by toughening mechanisms such as crack bridging shown in the HEC-(SiC)1.0 composite and crack deflection shown in the HEC-(SiC)3.0 composite (marked with white circles) in Figure 2.

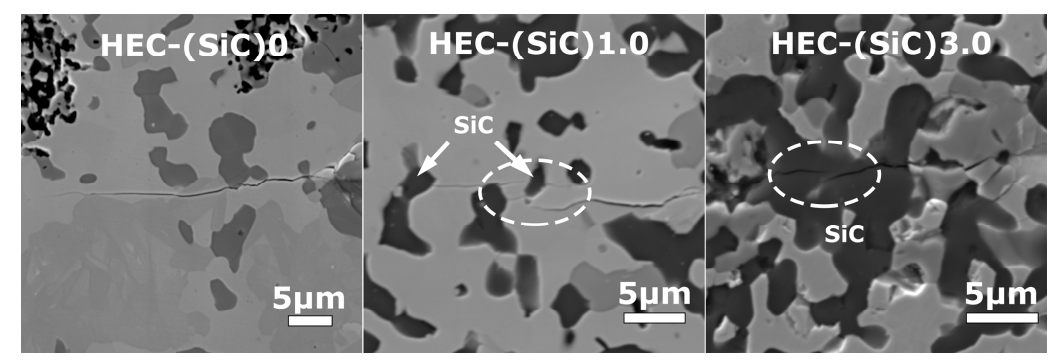

Figure 2. SEM micrographs of indentation cracks in HEC-(SiC)x composite sintered at $2000{ }^{\circ} \mathrm{C}$, under the indentation load of $1000 \mathrm{~g}$.

\subsection{SiC effect on Phase Fraction}

Figure 3 shows the backscattered electron (BSE) micrographs of the sintered HECs with different $\mathrm{SiC}$ content from $\mathrm{x}=0$ to 3.0. Each contrast in the microstructure refers to a region with a constant density due to the high sensitivity of the BSE detector to the atomic number, which is correlated directly to the material density [49]. The microstructures of HECs containing $\operatorname{SiC}(x=0.5,1.0,2.0$, and 3.0) consist of three distinct phases - bright, gray, and dark (marked as 1, 2, and 3 in the microstructure of HEC-(SiC)0.5 in Figure 3). Whereas the microstructure of HEC without addition of SiC (HEC-(SiC)0) show four different contrasts (marked as 1 to 4 in HEC-(SiC)0). According to energy-dispersive X-ray spectroscopy (EDS) analysis, the darkest region in all of the four HEC-(SiC)x compositions $(x=0.5$, 1.0, 2.0, and 3.0) refers to $\mathrm{SiC}$ and a trace amount of porosity present at the interface between the $\mathrm{SiC}$ phase and the adjacent phase, which was created during the grinding and polishing process. The SiC phase appears in different irregular shapes with lower aspect ratio than the original fiber-shaped whiskers, which could be a result of the morphology transformation of $\mathrm{SiC}_{\mathrm{w}}$ under the effect of elevated temperature. A similar morphology change of $\mathrm{SiC}_{\mathrm{w}}$ from a fiber-to particle-shaped structure at high temperatures has been observed by Cheng et al. [50] and Zhou et al. [51]. The volume fraction of the phases with a certain contrast are analyzed using the image analysis. In the bar chart in Figure 3 , each individual column refers to the $100 \mathrm{vol}$. \% of the corresponding specimen with the contribution of each phase to it, demonstrated by the length of the sub-columns marked with different grayscales. For the HEC-(SiC)0 composite that has four different contrasts, the two brightest phases are summarized in the bright sub-column. From $x=0$ to 3.0 in the HEC-(SiC)x system, regardless of the increase in the amount of $\mathrm{SiC}$, the ratio of the volume fraction between the gray and the bright phase rises from 0.36 to 0.76 . As the sintering parameters for all these five samples are the same, the experimental results suggest that the addition of $\mathrm{SiC}$ facilitated the formation of the gray phase over the formation of the bright phase. 


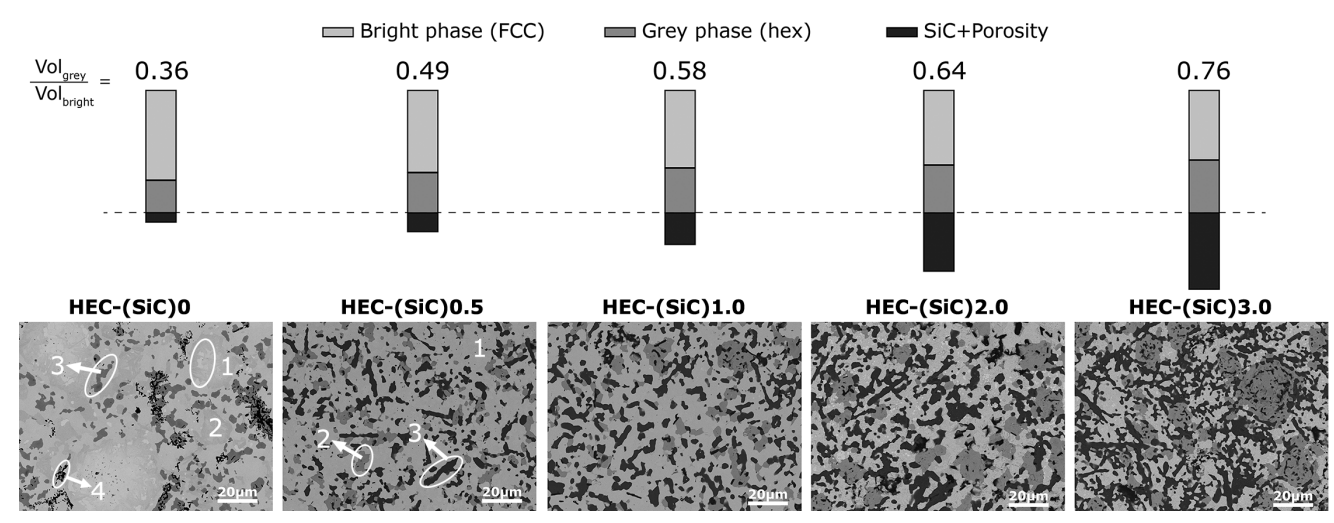

Figure 3. Backscattered electron micrographs of HEC with different $\mathrm{SiC}$ content sintered at $2000{ }^{\circ} \mathrm{C}$, the volume fraction ratio between the gray and bright phase shows increased amount of gray phase with increased $\mathrm{SiC}$ content.

According to the EDS results, both the gray and bright regions observed in all five composites contain four constituent metal elements- $\mathrm{Hf}, \mathrm{Mo}$, $\mathrm{Ta}$, and Ti-however, with different atomic compositions. For SiC-containing composites where only two visible contrasts, except for $\mathrm{SiC}$, were observed, carbon was detected in both of the phases while boron was only observed in the gray phase. EDS spectra collected from these gray and bright phases are similar among the HEC-(SiC)x composite, as shown in Figure 4, which were obtained from HEC-(SiC)1.0. It can be seen from the EDS spectra that the boron X-ray emission peak is absent in the bright phase yet displayed beside the carbon peak in the gray phase. The quantitative analysis shows that the gray phase has higher abundance of Mo and Ti than the bright phase, displaying significantly higher intensities of the correlated EDS peaks of Mo and Ti in the spectrum. The higher content of Mo and Ti in the gray phase can be confirmed in the EDS elemental maps in Figure 4. These results are in agreement with the darker contrast of the gray phase than the bright in the BSE microstructure, due to smaller atomic numbers of Mo and Ti compared to Hf and Ta. For the composition without $\mathrm{SiC}$ addition, HEC-(SiC)0, the spectra collected from the two brightest regions are similar with similar quantitative atomic compositions. The HECs synthesized at high temperatures could be meta-stable at room temperature, the microstructure and composition heterogeneity was possibly caused by spinodal decomposition during the cooling [15]. A similar decomposition phenomenon due to a different cooling rate throughout the specimen was observed in the high-entropy carbides by Castle et al. [2].
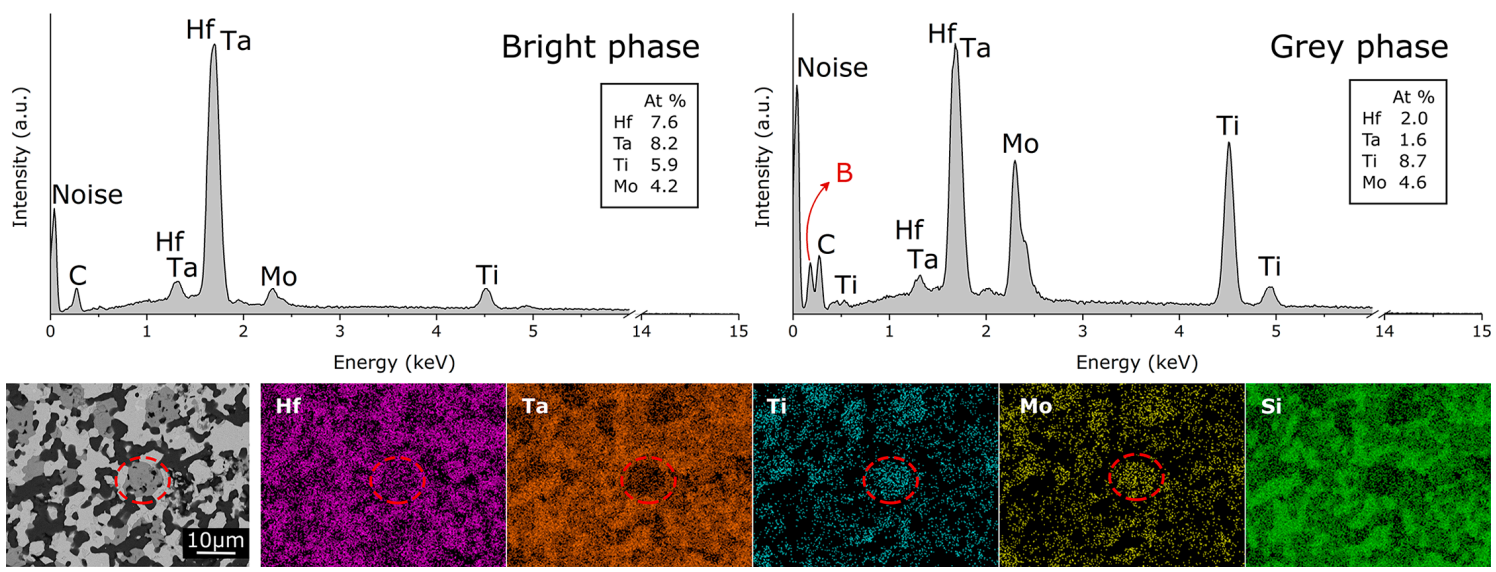

Figure 4. EDS spectra and mapping results of the bright and gray phase shown in the backscattered electron (BSE) microstructure, obtained from HEC-(SiC)1.0. 
Figure 5 shows the X-ray diffraction (XRD) patterns of the HEC ceramic composites sintered at $2000{ }^{\circ} \mathrm{C}$. It can be seen from Figure $5 \mathrm{a}$ that all HEC-(SiC)x composites contain an FCC phase (space group 225) and a hexagonal phase (space group 191). Due to the low diffraction intensities of several peaks, the XRD diffractograms were plotted in a logarithmical scale in Figure $5 b$ for clearer observation of the minor phases. A SiC diffraction peak at $2 \theta=35.5^{\circ}$ was observed in HEC-(SiC)x $(x=0.5,1,2,3)$ composites. The XRD patterns show that, except for the major FCC and hexagonal phase (marked as hexagonal (191)), the HEC-(SiC)0 composite contains one minor hexagonal phase (space group 189), one cubic phase (primitive cubic), and trace amounts of a tetrahedral phase. By increasing the SiC content in the HEC, major FCC and hexagonal (191) phases are retained, while the diffraction intensities of the tetrahedral, the hexagonal (189), and the primitive cubic phase gradually reduce and eventually become absent in the HEC-(SiC)3.0 composite. According to the discussion of the microstructures in Figure 3, the BSE micrographs of HEC-(SiC) $x(x=0.5,1.0,2.0,3.0)$ composites show only two distinct contrasts along with $\mathrm{SiC}$, while the XRD results reveal more than two phases for HEC-(SiC)x $(\mathrm{x}=$ $0.5,1.0,2.0)$. This could be due to the small amount of the tetrahedral phase to be observed in SEM, and secondly, the similar elemental compositions between the major FCC phase and the primitive cubic phase and between the two hexagonal phases, which made them indistinguishable based on the contrast difference in the BSE image. The hexagonal (191) phase shows lattice parameters of $\mathrm{a}=0.3051 \mathrm{~nm}$ and $\mathrm{c}=0.3237 \mathrm{~nm}$, while the FCC phase in all composites shows a lattice constant of approximately $0.447 \mathrm{~nm}$, which is close to the lattice parameter of the constituent metal carbides TaC $(0.446 \mathrm{~nm}$, ICDD 03-065-8792, $50.3 \mathrm{at} \% \mathrm{C})$. The phase formation mechanism discussed in our previous work on high-entropy boron-carbides [16,17] suggested that $\mathrm{TaC}$ was the host FCC lattice in the current carbide system so that other atoms migrate in and occupy the corresponding cationic and anionic sites in the $\mathrm{TaC}$ rocksalt structure, due to the lowest metal vacancy formation energy of $\mathrm{TaC}$ among the FCC carbides.
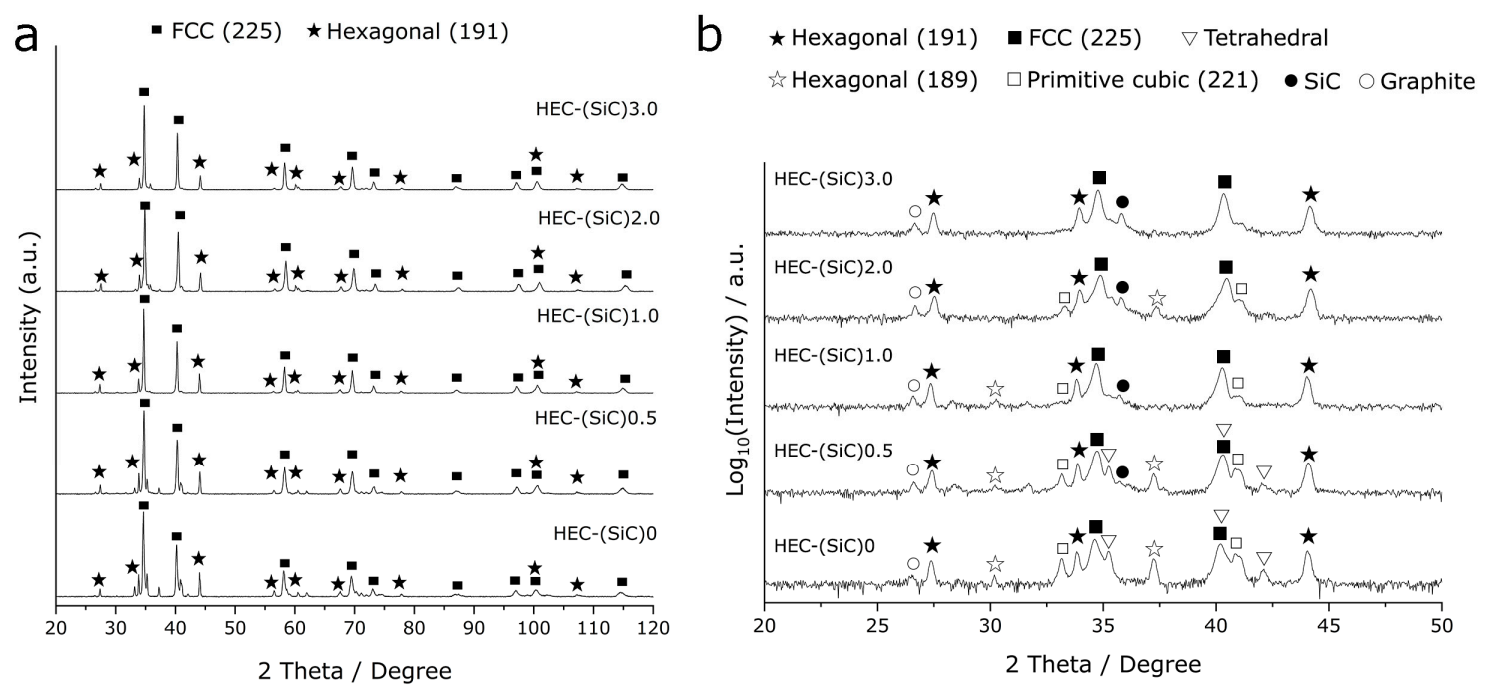

Figure 5. (a) X-ray diffractogram of HEC-(SiC)x composites sintered at $2000{ }^{\circ} \mathrm{C}$ (the corresponded space groups are marked in the bracket), (b) the intensities are plotted in logarithmic scale. The reduction of the number of the phases in the composites can be observed with increased SiC content.

Figure 6 shows the comparison of the XRD patterns of the as-mixed precursors and the HEC-(SiC)x composites sintered at different temperatures. It can be seen that phase transformation has not taken place at $1600{ }^{\circ} \mathrm{C}$. The FCC peaks start to converge at $1800{ }^{\circ} \mathrm{C}$, indicating the initial formation of the FCC-structured high-entropy ceramic phase. The strongest diffraction peak of the hexagonal (191) structure at $2 \theta=44^{\circ}$ (marked with the red arrow) started to be visible at $1800^{\circ} \mathrm{C}$, suggesting the initial formation of hexagonal phase at $180{ }^{\circ} \mathrm{C}$. The composition of HEC-(SiC)x composites at $2000{ }^{\circ} \mathrm{C}$ is similar to what was achieved in our previous study on the $\mathrm{B}_{4}\left(\mathrm{HfMo}_{2} \mathrm{TaTi}\right) \mathrm{C} / \mathrm{SiC}$ composite, however at 
lower temperature $\left(1800^{\circ} \mathrm{C}\right)$ [17], attributed to a higher heating rate applied in this study $\left(200{ }^{\circ} \mathrm{C} / \mathrm{min}\right.$ compare to $100{ }^{\circ} \mathrm{C} / \mathrm{min}$ ). Similar dependence of the sintering temperature on the heating rate in SPS has been reported $[52,53]$.

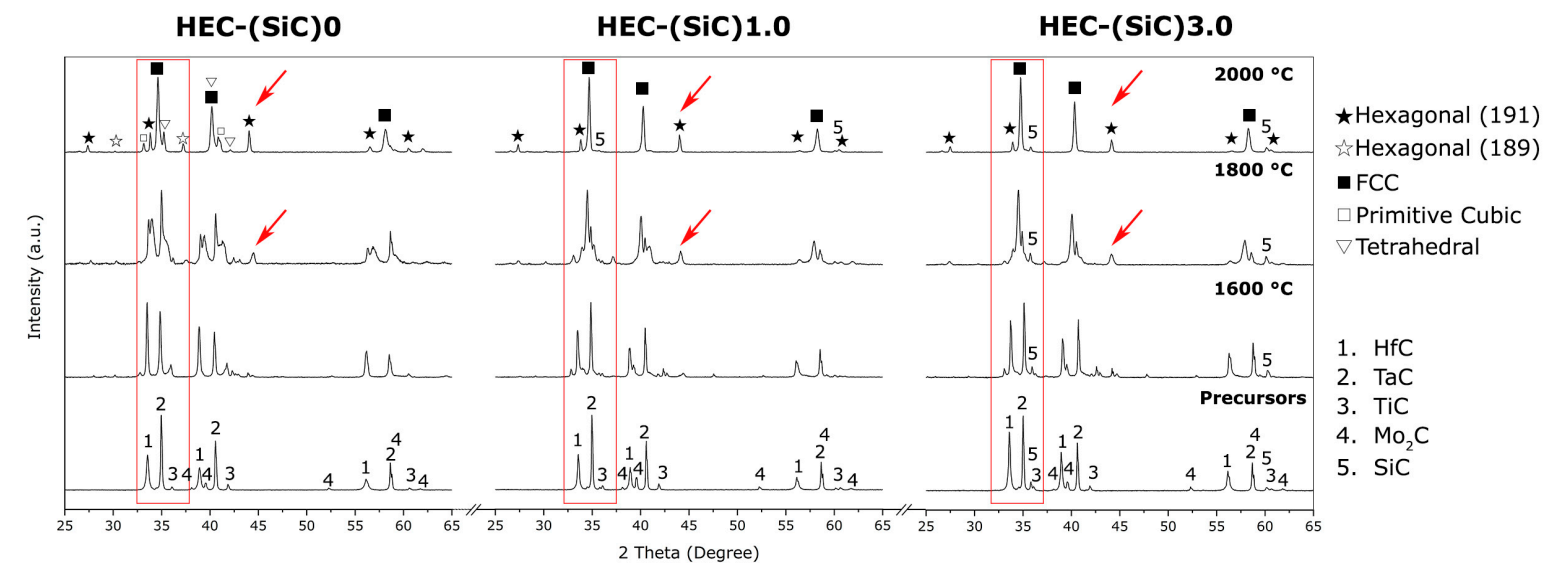

Figure 6. Composition evolution shown by X-ray diffractograms of HECs with temperature. The diffraction peaks of high-entropy face-centered cubic (FCC) and hexagonal phases start to be visible from $1800{ }^{\circ} \mathrm{C}$.

In a multiphase material, the diffracted intensity in XRD is determined by several factors, including the scattering factor of the elements, the content of the phase in the mixture, and the nature of the correlated crystal structure [54]. In principle, high volume fraction and high scattering factor of the constituent elements lead to high-diffracted intensity in the XRD diffractogram. According to the microstructure and EDS elemental analysis on HEC-(SiC)3.0, the bright phase dominates over the gray in volume fraction and shows a higher content of heavy elements such as Hf and Ta, which have greater scattering factors. Moreover, our work on the same high-entropy boron-carbide system has discovered that the high-entropy solid solution with the presence of boron showed hexagonal structure [17] as the gray phase in this study. It is therefore reasonable to conclude that the bright phase corresponds to the FCC and the gray phase containing a higher content of B has hexagonal crystal structure. Castle et al. [2] have reported that the incorporation of smaller atoms like Ti into TaC leads to the reduction of the lattices parameter. Hence, it is expected that during the phase transformation, higher Ti/Mo to Ta content in the gray phase (shown in Figure 4) can cause severe lattice distortion and may lead to the crystal structure change from a FCC to a hexagonal structure. On the other hand, the formation of a FCC-structured carbon-rich phase and a hexagonal-structured boron-rich phase with different elemental compositions can be explained by the formation energy difference of the corresponding metal carbides $(\mathrm{MC})$ and diborides $\left(\mathrm{MB}_{2}\right)$ calculated by the density functional theory [55]. The formation energy difference $E_{f}\left(M B_{2}\right)-E_{f}(M C)$ for Mo and Ti is more negative than that of Hf and Ta [56]. Therefore, Mo and Ti are more preferable to be dissolved in the hexagonal boride structure, which is in agreement with the EDS results shown in Figure 4 where the gray/hexagonal phase contains a higher content of Mo and Ti.

Thus, the effect on phase composition in the composites by increasing SiC content should be referred to the stabilization of a hexagonal-structured high-entropy phase (the gray region in the microstructure). However, it is interesting that the experimental results showed strong evidence of $\mathrm{SiC}$ facilitating the formation of the hexagonal phase but not being involved in the formation of high-entropy phases per se. Considering that the hexagonal and the FCC high-entropy phase is rich in boron and carbon, respectively, the favored formation of the boron-rich hexagon phase with increasing $\mathrm{SiC}$ content in the HEC-(SiC)x composites could lead to the formation of free carbon in the composite, which is related to the diffraction peak of graphite at $2 \theta=26.6^{\circ}$ in Figure $5 \mathrm{~b}$. A slight increase of the intensity of the carbon diffraction peak in Figure $5 \mathrm{~b}$ can be observed with increased $\mathrm{SiC}$ content, suggesting a higher amount of free carbon formation during the phase transformation. 
Carbon, as a commonly used sintering additive for UHTCs such as $\mathrm{ZrB}_{2}$ [57], $\mathrm{B}_{4} \mathrm{C}$ [58], and $\mathrm{SiC}$ [59], improves the sinterability by reacting with the surface oxide and enhancing grain boundary diffusion. The incorporation of $\mathrm{SiC}$ into UHTCs, such as metal diborides, as a sintering additive has also been reported to promote the grain-boundary diffusion and results in the high densification and strength of UHTCs [60]. Thus, in our case, the combination of $\mathrm{SiC}$ and the free carbon formation during the phase transformation from a FCC to a hexagonal high-entropy phase with increasing content of SiC contribute together to the promoted densification of the HEC-(SiC)x composites, as shown in Figure 1a.

All of the constituent metal elements in the present study have lower formation energy of $\mathrm{MB}_{2}$ than MC, which suggests that diboride instead of carbide is the energetically preferred phase in the current system [56]. Moreover, the diffusion rate of solute metal atoms into the TaC lattice has been discussed previously to be $\mathrm{Ti}>\mathrm{Mo}>\mathrm{Hf}$, thus the hexagonal structured high-entropy solid solution represents the energetical favorite phase in the high-entropy boron-carbide system due to the corresponding atomic composition ( $\mathrm{Ti}>\mathrm{Mo}>\mathrm{Hf}$, in Figure 4) with the diffusion priorities [17]. Hence, the stabilization of the hexagonal-structured high-entropy phase could be a result of promoted diffusion by $\mathrm{SiC}$ and free carbon. On the other hand, $\mathrm{SiC}$ addition limited the grain growth and thereby hindered the mass transport in HEC composites during the cooling process. As the formation of multiple cubic phases might be a result of spinodal decomposition of the major FCC phase during cooling, the hindering of mass transport by $\mathrm{SiC}$ can contribute to the stabilization of the high-entropy solid solution so that only one FCC phase was observed in the HEC-(SiC)3.0 composite.

\section{Conclusions}

High-entropy ceramic composites from multiple refractory carbide $\mathrm{HfC}, \mathrm{Mo}_{2} \mathrm{C}, \mathrm{TaC}, \mathrm{TiC}, \mathrm{B}_{4} \mathrm{C}$, and $\mathrm{SiC}$ were synthesized. The dependence of densification, microstructure, phase composition, and mechanical properties of the HECs composite on $\mathrm{SiC}$ content were investigated. The sintered HEC-(SiC)x composite showed promoted densification compared to HECs without SiC addition. With increasing the $\mathrm{SiC}$ content from HEC-(SiC)0 (0 vol. \%) to HEC-(SiC)3.0 (37 vol. \%), the HECs composites showed remarkable enhancement of the mechanical properties, including higher Vickers hardness from 20.3 to $26.9 \mathrm{GPa}$, under the load of $1000 \mathrm{~g}$, and improved fracture toughness from 3.14 to $5.95 \mathrm{MPa} \cdot \mathrm{m}^{1 / 2}$, attributed to the crack bridging and deflecting mechanism. The investigation on the phase composition in the HEC-(SiC)x composite showed that four different high-entropy phases could be formed, including three cubic crystal-structured phases and one hexagonal phase. However, only two high-entropy phases were retained when the SiC content was increased to 37 vol. \% (HEC-(SiC)3.0). The two retained high-entropy phases contained all metal elements, with the face-centered cubic (FCC) structure having relatively higher content of $\mathrm{Hf}, \mathrm{Ta}$, and $\mathrm{C}$, and the hexagonal crystal structure containing boron and a relatively higher amount of $\mathrm{Mo}$ and $\mathrm{Ti}$,. Composites with higher $\mathrm{SiC}$ content showed an increased volume formation of the hexagonal-structured phase, suggesting a favored formation of hexagonal-structured high-entropy phase due to $\mathrm{SiC}$ addition and the formation of free carbon.

Author Contributions: Conceptualization, H.Z. and F.A.; methodology, H.Z. and F.A.; formal analysis, H.Z.; investigation, H.Z.; writing-original draft preparation, H.Z.; writing-review and editing, H.Z. and F.A.; supervision, F.A.; project administration, F.A.; funding acquisition, F.A. All authors have read and agreed to the published version of the manuscript.

Funding: This work was supported by the Swedish Foundation for Strategic Research (SSF) for Infrastructure Fellowship, grant number RIF14-0083.

Conflicts of Interest: The authors declare no conflict of interest.

\section{References}

1. Bérardan, D.; Franger, S.; Dragoe, D.; Meena, A.K.; Dragoe, N. Colossal dielectric constant in high entropy oxides. Phys. Status Solidi-Rapid Res. Lett. 2016, 10, 328-333. [CrossRef]

2. Castle, E.; Csanádi, T.; Grasso, S.; Dusza, J.; Reece, M. Processing and Properties of High-Entropy Ultra-High Temperature Carbides. Sci. Rep. 2018, 8, 1-12. [CrossRef] [PubMed] 
3. Gild, J.; Zhang, Y.; Harrington, T.; Jiang, S.; Hu, T.; Quinn, M.C.; Mellor, W.M.; Zhou, N.; Vecchio, K.; Luo, J. High-Entropy Metal Diborides: A New Class of High-Entropy Materials and a New Type of Ultrahigh Temperature Ceramics. Sci. Rep. 2016, 6, 37946. [CrossRef] [PubMed]

4. Yeh, J.W.; Chen, S.K.; Lin, S.J.; Gan, J.Y.; Chin, T.S.; Shun, T.T.; Tsau, C.H.; Chang, S.Y. Nanostructured high-entropy alloys with multiple principal elements: Novel alloy design concepts and outcomes. Adv. Eng. Mater. 2004, 6, 299-303. [CrossRef]

5. Oses, C.; Toher, C.; Curtarolo, S. High-entropy ceramics. Nat. Rev. Mater. 2020, 5, 295-309. [CrossRef]

6. Ye, B.; Wen, T.; Nguyen, M.C.; Hao, L.; Wang, C.Z.; Chu, Y. First-principles study, fabrication and characterization of $\left(\mathrm{Zr}_{0.25} \mathrm{Nb}_{0.25} \mathrm{Ti}_{0.25} \mathrm{~V}_{0.25}\right) \mathrm{C}$ high-entropy ceramics. Acta Mater. 2019, 170, 15-23. [CrossRef]

7. Ye, B.; Wen, T.; Huang, K.; Wang, C.; Chu, Y. First-principles study, fabrication, and characterization of $\left(\mathrm{Hf}_{0.2} \mathrm{Zr}_{0.2} \mathrm{Ta}_{0.2} \mathrm{Nb}_{0.2} \mathrm{Ti}_{0.2}\right) \mathrm{C}$ high-entropy ceramic. J. Am. Ceram. Soc. 2019, 102, 4344-4352. [CrossRef]

8. Sarker, P.; Harrington, T.; Toher, C.; Oses, C.; Samiee, M.; Maria, J.P.; Brenner, D.W.; Vecchio, K.S.; Curtarolo, S.; Harrington, T.; et al. High-entropy high-hardness metal carbides discovered by entropy descriptors. Nat. Commun. 2018, 9, 1-10. [CrossRef]

9. Dai, F.Z.; Wen, B.; Sun, Y.; Xiang, H.; Zhou, Y. Theoretical prediction on thermal and mechanical properties of high entropy $\left(\mathrm{Zr}_{0.2} \mathrm{Hf}_{0.2} \mathrm{Ti}_{0.2} \mathrm{Nb}_{0.2} \mathrm{Ta}_{0.2}\right) \mathrm{C}$ by deep learning potential. J. Mater. Sci. Technol. 2020, 43, 168-174. [CrossRef]

10. Yan, X.; Constantin, L.; Lu, Y.; Silvain, J.F.; Nastasi, M.; Cui, B. $\left(\mathrm{Hf}_{0.2} \mathrm{Zr}_{0.2} \mathrm{Ta}_{0.2} \mathrm{Nb}_{0.2} \mathrm{Ti}_{0.2}\right) \mathrm{C}$ high-entropy ceramics with low thermal conductivity. J. Am. Ceram. Soc. 2018, 101, 4486-4491. [CrossRef]

11. Gild, J.; Braun, J.; Kaufmann, K.; Marin, E.; Harrington, T.; Hopkins, P.; Vecchio, K.; Luo, J. A high-entropy silicide: $\left(\mathrm{Mo}_{0.2} \mathrm{Nb}_{0.2} \mathrm{Ta}_{0.2} \mathrm{Ti}_{0.2} \mathrm{~W}_{0.2}\right) \mathrm{Si}_{2}$. J. Mater. 2019, 5, 337-343. [CrossRef]

12. Qin, Y.; Liu, J.X.; Li, F.; Wei, X.; Wu, H.; Zhang, G.J. A high entropy silicide by reactive spark plasma sintering. J. Adv. Ceram. 2019, 8, 148-152. [CrossRef]

13. Ye, B.; Ning, S.; Liu, D.; Wen, T.; Chu, Y. One-step synthesis of coral-like high-entropy metal carbide powders. J. Am. Ceram. Soc. 2019, 102, 6372-6378. [CrossRef]

14. Dusza, J.; Švec, P.; Girman, V.; Sedlák, R.; Castle, E.G.; Csanádi, T.; Kovalčíková, A.; Reece, M.J. Microstructure of (Hf-Ta-Zr-Nb)C high-entropy carbide at micro and nano/atomic level. J. Eur. Ceram. Soc. 2018, 38, 4303-4307. [CrossRef]

15. Zhang, R.; Reece, M.J. Review of high entropy ceramics: Design, synthesis, structure and properties. J. Mater. Chem. A 2019, 7, 22148-22162. [CrossRef]

16. Zhang, H.; Hedman, D.; Feng, P.; Han, G.; Akhtar, F.; Akhta, F. A high-entropy $\mathrm{B}_{4}\left(\mathrm{HfMo}_{2} \mathrm{TaTi}\right) \mathrm{C}$ and $\mathrm{SiC}$ ceramic composite. Dalt. Trans. 2019, 48, 5161-5167. [CrossRef]

17. Zhang, H.; Akhtar, F. Processing and Characterization of Refractory Quaternary and Quinary High-Entropy Carbide Composite. Entropy 2019, 21, 474. [CrossRef]

18. Pierson, H.O. Handbook of Refractory Carbides and Nitrides: Properties, Characteristics, Processing and Applications; William Andrew: Norwich, NY, USA, 1996; ISBN 081551770X.

19. Upadhya, K.; Yang, J.M.; Hoffman, W.P. Advanced materials for ultrahigh temperature structural applications above $2000{ }^{\circ} \mathrm{C}$. Am. Ceram. Soc. Bull 1997, 76, 51-56.

20. Sciti, D.; Monteverde, F.; Guicciardi, S.; Pezzotti, G.; Bellosi, A. Microstructure and mechanical properties of $\mathrm{ZrB}_{2}-\mathrm{MoSi}_{2}$ ceramic composites produced by different sintering techniques. Mater. Sci. Eng. A 2006, 434, 303-309. [CrossRef]

21. Ghaffari, S.A.; Faghihi-Sani, M.A.; Golestani-Fard, F.; Mandal, H. Spark plasma sintering of TaC-HfC UHTC via disilicides sintering aids. J. Eur. Ceram. Soc. 2013, 33, 1479-1484. [CrossRef]

22. Pastor, H. Metallic borides: Preparation of solid bodies-Sintering methods and properties of solid bodies. In Boron and Refractory Borides; Springer: Berlin, Heidelberg, Germany, 1977; pp. 457-493.

23. Monteverde, F.; Bellosi, A. Beneficial effects of AlN as sintering aid on microstructure and mechanical properties of hot-pressed $\mathrm{ZrB}_{2}$. Adv. Eng. Mater. 2003, 5, 508-512. [CrossRef]

24. Levine, S.R.; Opila, E.J.; Halbig, M.C.; Kiser, J.D.; Singh, M.; Salem, J.A. Evaluation of ultra-high temperature ceramics foraeropropulsion use. J. Eur. Ceram. Soc. 2002, 22, 2757-2767. [CrossRef]

25. Sciti, D.; Silvestroni, L. Processing, sintering and oxidation behavior of $\mathrm{SiC}$ fibers reinforced $\mathrm{ZrB}_{2}$ composites. J. Eur. Ceram. Soc. 2012, 32, 1933-1940. [CrossRef]

26. Monteverde, F.; Savino, R. Stability of ultra-high-temperature $\mathrm{ZrB}_{2}$-SiC ceramics under simulated atmospheric re-entry conditions. J. Eur. Ceram. Soc. 2007, 27, 4797-4805. [CrossRef] 
27. Monteverde, F.; Bellosi, A. Microstructure and properties of an $\mathrm{HfB}_{2}-\mathrm{SiC}$ composite for ultra high temperature applications. Adv. Eng. Mater. 2004, 6, 331-336. [CrossRef]

28. Low, I.M. Advances in Ceramic Matrix Composites; Woodhead Publishing: Cambridge, UK, 2018; ISBN 0081021674.

29. Han, F.; Zhong, Z.; Zhang, F.; Xing, W.; Fan, Y. Preparation and Characterization of SiC Whisker-Reinforced $\mathrm{SiC}$ Porous Ceramics for Hot Gas Filtration. Ind. Eng. Chem. Res. 2015, 54, 226-232. [CrossRef]

30. Liu, D.; Gao, Y.; Liu, J.; Li, K.; Liu, F.; Wang, Y.; An, L. SiC whisker reinforced $\mathrm{ZrO}_{2}$ composites prepared by flash-sintering. J. Eur. Ceram. Soc. 2016, 36, 2051-2055. [CrossRef]

31. Chamberlain, A.L.; Fahrenholtz, W.G.; Hilmas, G.E.; Ellerby, D.T. High-strength zirconium diboride-based ceramics. J. Am. Ceram. Soc. 2004, 87, 1170-1172. [CrossRef]

32. Wang, J.; Lin, W.; Jiang, Z.; Duan, L.; Yang, G. The preparation and properties of $\mathrm{SiC}_{\mathrm{W}} / \mathrm{B} 4 \mathrm{C}$ composites infiltrated with molten silicon. Ceram. Int. 2014, 40, 6793-6798. [CrossRef]

33. Malmal Moshtaghioun, B.; Ortiz, A.L.; Gómez-García, D.; Domínguez-Rodríguez, A. Toughening of super-hard ultra-fine grained B4C densified by spark-plasma sintering via SiC addition. J. Eur. Ceram. Soc. 2013, 33, 1395-1401. [CrossRef]

34. Zimmermann, J.W.; Hilmas, G.E.; Fahrenholtz, W.G. Thermal shock resistance of $\mathrm{ZrB}_{2}$ and $\mathrm{ZrB}_{2}-30 \% \mathrm{SiC}$. Mater. Chem. Phys. 2008, 112, 140-145. [CrossRef]

35. Wang, H.; Cao, Y.; Liu, W.; Wang, Y. Oxidation behavior of $\left(\mathrm{Hf}_{0.2} \mathrm{Ta}_{0.2} \mathrm{Zr}_{0.2} \mathrm{Ti}_{0.2} \mathrm{Nb}_{0.2}\right) \mathrm{C}-\mathrm{xSiC}$ ceramics at high temperature. Ceram. Int. 2020, 46, 11160-11168. [CrossRef]

36. Lu, K.; Liu, J.X.; Wei, X.F.; Bao, W.; Wu, Y.; Li, F.; Xu, F.; Zhang, G.J. Microstructures and mechanical properties of high-entropy (Ti0.2Zr0.2Hf0.2Nb0.2Ta0.2)C ceramics with the addition of SiC secondary phase. J. Eur. Ceram. Soc. 2020, 40, 1839-1847. [CrossRef]

37. Evans, A.G.; Charles, E.A. Fracture toughness determinations by indentation. J. Am. Ceram. Soc. 1976, 59, 371-372. [CrossRef]

38. Rocha-Rangel, E. Fracture toughness determinations by means of indentation fracture. In Nanocomposites with Unique Properties and Applications in Medicine and Industry; IntechOpen: London, UK, 2011; pp. 21-38.

39. Blendell, J.E. Solid-state Sintering. In Encyclopedia of Materials: Science and Technology, 2nd ed.; Cahn, K.H.J., Flemings, R.W., Ilschner, M.C., Kramer, B., Mahajan, E.J., Veyssière, S., Eds.; Elsevier: Oxford, UK, 2001; pp. 8745-8750. ISBN 978-0-08-043152-9.

40. Weiser, M.W. Pressureless Sintering of Ceramic Composites; New Mexico Univ Albuquerque, 1994; Available online: https://apps.dtic.mil/dtic/tr/fulltext/u2/a277274.pdf (accessed on 18 September 2020).

41. Tiegs, T.N.; Dillard, D.M. Effect of Aspect Ratio and Liquid-Phase Content on Densification of Alumina-Silicon Carbide Whisker Composites. J. Am. Ceram. Soc. 1990, 73, 1440-1442. [CrossRef]

42. Wei, W.C.; Novich, B.E. Method for Preparing Dense, Pressureless Sintered SiC Whisker Reinforced Composite Ceramics. U.S. Patent 4,946,808, 7 August 1990.

43. Silvestroni, L.; Sciti, D.; Melandri, C.; Guicciardi, S. Toughened ZrB2-based ceramics through SiC whisker or SiC chopped fiber additions. J. Eur. Ceram. Soc. 2010, 30, 2155-2164. [CrossRef]

44. Cavaliere, P. Spark Plasma Sintering of Materials: Advances in Processing and Applications; Springer: Berlin/Heidelberg, Germany, 2019; ISBN 303005327X.

45. Farhadi, K.; Sabahi Namini, A.; Shahedi Asl, M.; Mohammadzadeh, A.; Ghassemi Kakroudi, M. Characterization of hot pressed $\mathrm{SiC}$ whisker reinforced $\mathrm{TiB}_{2}$ based composites. Int. J. Refract. Met. Hard Mater. 2016, 61, 84-90. [CrossRef]

46. Shahedi Asl, M.; Ahmadi, Z.; Sabahi Namini, A.; Babapoor, A.; Motallebzadeh, A. Spark plasma sintering of TiC-SiCw ceramics. Ceram. Int. 2019, 45, 19808-19821. [CrossRef]

47. Liu, Q.; Han, W.; Zhang, X.; Wang, S.; Han, J. Microstructure and mechanical properties of ZrB $\mathrm{r}_{2}-\mathrm{SiC}$ composites. Mater. Lett. 2009, 63, 1323-1325. [CrossRef]

48. Phys, A.; Peng, C.; Gao, X.; Wang, M.; Wu, L.; Tang, H.; Li, X.; Zhang, Q.; Ren, Y. Diffusion-controlled alloying of single-phase multi-principal transition metal carbides with high toughness and low thermal diffusivity Diffusion-controlled alloying of single-phase multi-principal transition metal carbides with high toughness and low thermal diffusivity. Appl. Phys. Lett. 2019, 114, 011905. [CrossRef]

49. Goldstein, J.I.; Newbury, D.E.; Michael, J.R.; Ritchie, N.W.M.; Scott, J.H.J.; Joy, D.C. Scanning Electron Microscopy and X-Ray Microanalysis; Springer: Berlin/Heidelberg, Germany, 2017; ISBN 1493966766. 
50. Cheng, C.; Li, H.; Fu, Q.; Li, L.; Guo, L.; Yin, X.; Tian, X. Effects of pyrocarbon on morphology stability of SiC nanowires at high temperatures. J. Am. Ceram. Soc. 2018, 101, 3694-3702. [CrossRef]

51. Zhou, Y.; Xia, F. Effect of processing temperature on the morphology of silicon carbide whiskers. J. Am. Ceram. Soc. 1991, 74, 447-449. [CrossRef]

52. Biesuz, M.; Saunders, T.G.; Chen, K.; Bortolotti, M.; Salvo, M.; Grasso, S.; Reece, M.J. Interfacial reaction between $\mathrm{ZrNbHfTa}$ foil and graphite: Formation of high-entropy carbide and the effect of heating rate on its microstructure. J. Eur. Ceram. Soc. 2020, 40, 2699-2708. [CrossRef]

53. Laszkiewicz-Łukasik, J.; Jaworska, L.; Putyra, P.; Klimczyk, P.; Garzeł, G. The influence of SPS heating rates on the synthesis reaction of tantalum diboride. Boletín la Soc. Española Cerámica y Vidr. 2016, 55, 159-168. [CrossRef]

54. Suryanarayana, C.; Norton, M.G. X-ray Diffraction: A Practical Approach; Springer: Boston, MA, USA, 1998; ISBN 978-1-4899-0148-4.

55. Qin, M.; Gild, J.; Hu, C.; Wang, H.; Hoque, M.S.B.; Braun, J.L.; Harrington, T.J.; Hopkins, P.E.; Vecchio, K.S.; Luo, J. Dual-phase high-entropy ultra-high temperature ceramics. J. Eur. Ceram. Soc. 2020, 4, 5037-5050. [CrossRef]

56. Jain, A.; Ong, S.P.; Hautier, G.; Chen, W.; Richards, W.D.; Dacek, S.; Cholia, S.; Gunter, D.; Skinner, D.; Ceder, G.; et al. The Materials Project: A materials genome approach to accelerating materials innovation. APL Mater. 2013, 1, 11002. [CrossRef]

57. Fahrenholtz, W.G.; Hilmas, G.E.; Zhang, S.C.; Zhu, S. Pressureless Sintering of Zirconium Diboride: Particle Size and Additive Effects. J. Am. Ceram. Soc. 2008, 91, 1398-1404. [CrossRef]

58. Schwetz, K.A.; Grellner, W. The influence of carbon on the microstructure and mechanical properties of sintered boron carbide. J. Less Common Met. 1981, 82, 37-47. [CrossRef]

59. Wroblewska, G.H.; Nold, E.; Thümmler, F. The role of boron and carbon additions on the microstructural development of pressureless sintered silicon carbide. Ceram. Int. 1990, 16, 201-209. [CrossRef]

60. Fahrenholtz, W.G.; Wuchina, E.J.; Lee, W.E.; Zhou, Y. Ultra-High Temperature Ceramics: Materials for Extreme Environment Applications; John Wiley \& Sons: Hoboken, NJ, USA, 2014; ISBN 111892441X.

(C) 2020 by the authors. Licensee MDPI, Basel, Switzerland. This article is an open access article distributed under the terms and conditions of the Creative Commons Attribution (CC BY) license (http://creativecommons.org/licenses/by/4.0/). 